\title{
The importance of accessible design in education
}

\author{
Marina Beneito Pastor, Adelina Bolta Escolano
}

Universitat Politècnica de València, Valencia, España, marinabeneito@gmail.com, abolta@dpi.upv.es

\begin{abstract}
Accessible design is crucial on education because it provides equally opportunities of fulfilling everyone's potential, and it helps the education community to transmit the values of an openminded and empathic society where its diversity is standardised. Children realise about this diversity from the very early stages and won't be able to learn these values naturally if they are not equally able to interact with the environment that surrounds them. A link between designers and educators must be created in order to include accessible and assistive products in every education facility and exchange their experiences and opinions, so the design of accessible products, environments and services solves real needs and keeps improving.
\end{abstract}

Keywords: Education, inclusion, inclusive education, accessible design, universal design, design for all.

\section{Introduction}

This research pretends to expand and spread the essay "Universal Design for children", written by myselt at the The Institute of Technology of Carlow, during my Erasmus Academic year there, in Ireland, where I had the opportunity of choosing the subject I wanted to research about. So I decided to exploded to explore a design dimension in wich I am really interested, the accessible desing, in a context essencial for the improvement of our society: the education.

It is a fact that the products and environments we live in define our daily actions, and these actions will become our habits, habits that will influence our values and even culture. Nowadays, people without any disability spend $40 \%$ of our lifetime struggling with the environment. We tempt to think it is normal for products, services and environments to be design for "normal" or average users. However, the actual normal thing about the human race is diversity. So the environment should be designed to adapt its features to our diversity and necessities (M. Beneito, 2017).

The aim of this document is to invite the education community to think about the importance of accessible design in education, in every classroom, canteen or sport facility. 
This concept and others like Universal Design, Design for all, inclusive practices, assistive products, etc. might be unknown by several educators but they have a significant impact on education because they benefit both people with and without functional diversity by providing equally opportunities to fulfil everyone's potential. They can successfully help people with functional diversity to learn academic knowledge, but most importantly they enhance the possibilities of teaching to everybody the values and the openminded mindset to achieve an equitable, empathic and caring society, where its diversity is standardized.

The first step to achive the inclusion of people who are in risk of social exclusion is to introduce Accessible Design in education. Children realise about difference and diversity from the very early stages. They learn how to react from what they see and from their interactions with other children and with the environment that surrounds them. If they can equally interact with the environment it will make easier to understand we all have amazing abilities and to transmit empathic and caring values.

There are a big number of assistive products and products and environments specially designed for all, that can help the inclusion of people with functional diversity in the education system. However, a link between designers and educators must be created in order to include these products in every education facility, get feedback from children and the education community and keep developing the design of products, environments and services that solve real and actual needs (M. Beneito, 2017).

To sum up, inclusive practices and inclusive education methodologies should be included in the education system, however, they will need an accessible environment to succeed.

\section{Accessible design}

Universal Design and Design for All are terms that refer to the same design philosophy and methodology. In fact, they are consider sinonimous. Design for All has appeared reacently and it is more used by these professions' scope of practice, as well as inclusive design. Accessible is its main feature, and Accessible Design is the term used to refer to this concept in nonprofessional contexts.

Once we have cleared this point, Design for All means designing products and services considering that:

-Every environment we live in, is designed by humans for humans, so it is the environment which has to adapt to our necessities, not the other way around.

-There is a large number of potencial users with diverse phisic, cognitive or sensory characteristics, cultural background or dimensions.

-Users change over time as well as their capacities do.

-Users are the best source of information to design products and services that respond their needs and expectations. 
In other words, Design for all or Universal Design stands up for the design of products, environments and services that enables confidently and equally participation and interaction with the world to everyone as independently as possible in everyday life activities.

(The Commission for Architecture and the Built Environment, 2006).

The social agents directly involve on the achievement of the application of accessible design in our society are: users, companies, designers/ingeneers/professionals, public administration, education and non-governmental organizations.

In fact, the education community is, at the same time, user and part of the public education. As well as books, websites, videos, games, etc. the environment and the products that are part of the education facility are another tool to transmit knowledge and values.

\subsection{Principles}

It was Ronald Mace working hand by hand with a working group of engineers, product designers, environmental design researchers and architects, who developed the 7 Principles of universal design in 1997, in the North Carolina State University. These principles have been improve and developed over the years, and have been the essence of what today is known as Design for All. The objective of this principles is to guide architects, environment, product or communications designers, as well as other kind of engineers, in order to achieve the Design for All goals. Furthermore, they are used to evaluate existing products/services/environments to get better solutions and make both designers and users aware of its importance and good impact in our society (Centre for Excellence in Universal Design, 20149.

1. "Equitable use"

It sets that the design has to be readily saleable and useful to people in all their diversity. In other words, to fulfil this principle, the design has to be attractive to all users, keep away from segregation, equally provide security and privacy and own the same meaning of use for all consumers.

2. "Flexibility in use"

It refers to the number of possibilities in use that meet a broad range of user preferences and capacities. Thus, it has to provide different methods of use between choosing from, be accessible to right-handed and left-handed, accommodate the user's rate and enable user's exactitude and sureness.

3. "Simple and intuitive use"

The design can be easily understood and use despite user's knowledge, concentration ability, language skills or experience. To achieve this, it has to avoid complexity, provide 
feedback at each stage, communicate the importance of the information, provide different languages and literacy skills and be consequent with user intuition and expectation.

4. "Perceptible information"

The indispensable information related to the design has to be efficiently communicated to all possible users in spite of their sensory abilities or the ambient conditions. To reach this principle, the design has to maximize the information "legibility", distinguish different elements, as well as the important information from its surroundings and use different communication techniques to provide compatibility with devices used by people with sensory difficulties (tactile, verbal, pictorial...).

5. "Tolerance for error"

The design has to reduce as far as possible any adverse consequence of involuntary or accidental actions. It has to persuade against this unconscious actions in tasks, provide warning feedbacks from errors, as well as fail safe features, and avoid hazardous elements.

6. "Low physical effort"

It can be used conveniently and efficiently with minimum physical effort. It can be achieved maintaining the neutral body user position, minimizing repetitious actions and demanding reasonable executing forces and movements.

7. "Size and space for approach and use"

It refers to the dimensions of the design. They have to fit all user's body sizes, postures and mobility abilities for its use, manipulation, approach or reach. The key gaols in this principle are: providing a clear line of sight to the design elements from a stood or seated position, enabling different hand and grip sizes, providing enough space for the use of personal assistance devices and ensuring comfortable reach to all components for any standing or seated user.

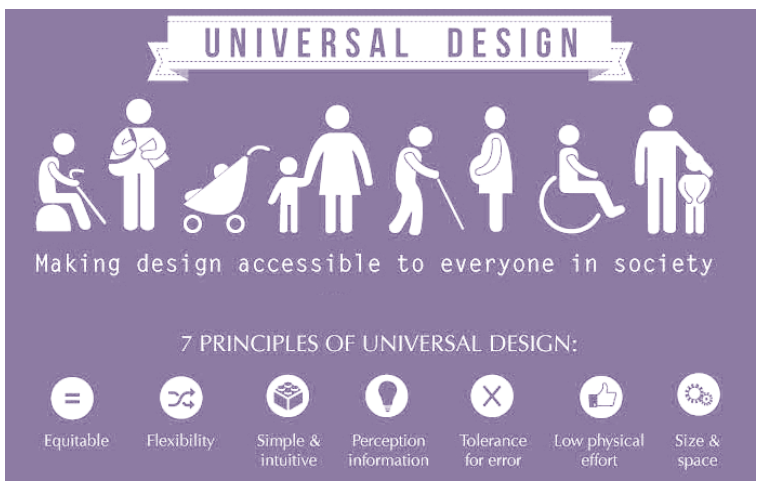

Illustration 1. Universal Design and its principles 


\section{Inclusion in early childhood}

Our world is currently facing growing populations with disabilities and, as well as the social and economic issues associated with this reality. The number of diverse people with different religions, traditions, actitudes, etc. that attends the classrooms is also increasing. The response of the educational system and the product design community in the following decades will directly impact on million people's lives all over the world (Bhatia, 2015).

"The disabled are not just some small, disenfranchised group: they represent all of us. So the first step is education, awareness and empathy." (D. Norman, 2009).

The raising awareness of the importance of inclusion should start as soon as possible in the education system because children do realise about difference/diversity from the early stages. What they learn about it and how they respond to that difference is critically important. Children learn from what they see and from their own interactions with other children and the environment that surround them. Thus, first of all, the role of families and monitors is crucial. Children will imitate their responses to situations and their behaviour with others. Depending on the positive or negative attitudes learned, they will engage more actively as they grew, fulfilling their own potential. Secondly, families and monitors have, as well, the responsibility to guide children interactions between each other in the best way as possible (Murray and Urban, 2012). And, finally, the product design community, together with architects and other design engineers, are responsible for children's interaction with the environment (Centre for Excellence in Universal Design, 2014). Then, it is obvious that inclusive practices should be embedded since the early years, but what is inclusion about?

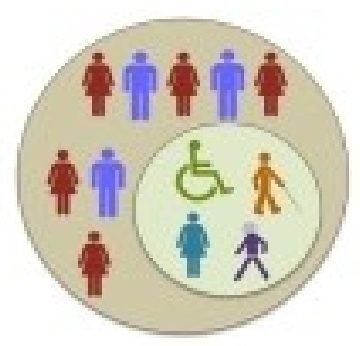

INTEGRATION

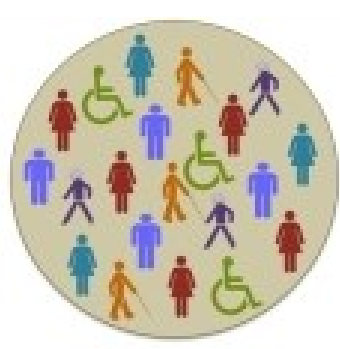

INCLUSION

Illustration 2. Integration versus inclusion

Inclusion is usually related to location, in other words, children are included if they share the same space. However, successful inclusive practices are not just with location. They follow a sociology that meets and understands all individual needs and tries to achieve the inclusion through changing the environment, since it is in the environment and not in the individual where there are the root causes and the root solutions to the exclusive practises. This is the main difference between inclusion and integration, thus the integration ideology 
attempt to change the individual to be able to becoming part of a group. Finally, inclusion is not only about practicalities. It is true is has not a conceptual focus, but an operational one. However, it should be seen as an attitude of mind for a normal worldview. For example, a "wheelchair ramp" should not signify more inclusion than anything else, thus it benefits everyone, not only wheelchair users (Nutbrown, Clough, and Atherton, 2013).

To sum up, inclusion is about how people interact with each other and about creating an equitable society in which everybody has the same opportunities to fulfil his/her potential (Nutbrown, Clough, and Atherton, 2013). Therefore, as soon as it is embedded, diversity will be welcoming, valued and celebrated as part of life (Murray and Urban, 2012).

\section{The role of desing in inclusion in early education}

Playing is the most important activity for children. It helps to develop their social, communication, problem-solving and motor and cognitive skills, as well as their attention, memory, creativity, emotional regulation... Tsai Lu Liu (2007) even defines play as the childhood occupation. However, not all the children have the same opportunities to play. Children with disabilities are limited because of their own abilities restrictions and due to the absence of consideration in the design of play products. Breaking down barriers between products and children with disabilities is the role of product design in inclusion in the early years. When children will be able to equally use and interact with all environments, services and products, the exclusion practices will be minimum (Preiser et al., 2010).

The table below will explain the principles of Universal Design in play children products (Mistrett \& Ruffino, 2011).

Table 1. Principles of Universal Design in play children products

\begin{tabular}{|c|c|}
\hline 1. Equitable use & $\begin{array}{l}\text { All children should use the same/equivalent means of access when } \\
\text { playing with the toy. The access and output features of the toy should } \\
\text { appeal to a variety of interests and needs of all children. }\end{array}$ \\
\hline 2. Flexibility in use & $\begin{array}{l}\text { The toy is adjustable. Include features for adaptable range of users. } \\
\text { Output is varied and adjustable; e.g. light + sound, vibration + sound, } \\
\text { volume, etc. }\end{array}$ \\
\hline 3. Simple and intuitive use & $\begin{array}{l}\text { How to play with the toy is clear. Non-complex, intuitive designs; e.g. } \\
\text { well defined access areas with consistent responses. Controls should } \\
\text { be obvious and accessible. }\end{array}$ \\
\hline 4. Perceptible information & $\begin{array}{l}\text { The toy is appealing. Use multiple modes (visual, sound and texture) } \\
\text { to highlight access and differentiate responses. }\end{array}$ \\
\hline 5. Tolerance for error & $\begin{array}{l}\text { The toy includes fail secure features and warning feedbacks from } \\
\text { errors. }\end{array}$ \\
\hline 6. Low physical effort & $\begin{array}{l}\text { Physical effort should be minimized with light to moderate force for } \\
\text { operation. A variety of motions can be used to access toys (e.g. bat, } \\
\text { press, drop, bang, etc.). }\end{array}$ \\
\hline $\begin{array}{l}\text { 7. Size and space for } \\
\text { approach and use }\end{array}$ & $\begin{array}{l}\text { Toy can be used in a variety of positions (sitting, standing, playing on } \\
\text { the floor or on a supporting surface). }\end{array}$ \\
\hline
\end{tabular}


There are two different methodologies to design Universal Design products for children. Both apply to the Principles of Universal Design, however, they have a different starting points. On one hand, a "From-able-to-disable" approach consists in including universal design features in toys designed for children without disabilities in order to expand their target user groups and benefit more children. On the other hand, a "From-disabled-to-able" approach provides broaden play possibilities for children with disabilities, because it aims to meet the needs of children without disabilities in the therapeutic products. Then, the playability and the aesthetic values of mainstream play children products and the skill development approach from therapeutic products meet in one unique design for the benefit of both children with and without disabilities (Tsai Lu Liu, 2007). In addition, the production volume will increase for the wider market and could decrease the product cost to make them more affordable (Schrott, 2009).

"Let's Play", developed at the University of Buffalo (New York), was the first program to apply the "From-disable-to-able" methodology. From 1998, it provides guidelines and collaborates with companies to included universal design in toy products. "Play Racer" is one of its successful projects. It aimed to design a play product that children with and without lower extremity disabilities can control and ride in a fun way while developing their physical coordination and upper extremity strength (Letsplay.buffalo.edu, 2011). The image bellow shows the design process followed by this project.

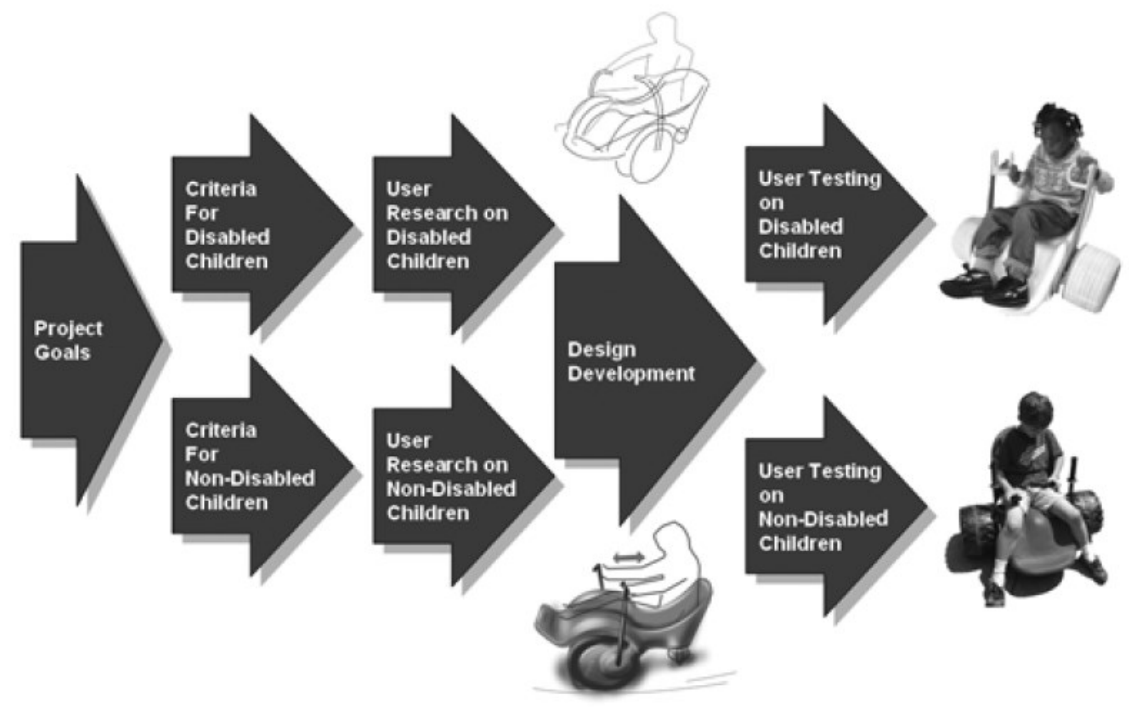

Illustration 3. Play Racer Design Process 
The resulting design is an authentic Design for All product, firstly identify as a toy, secondly as a therapeutic product, and valued for both children market segments (Tsai Lu Liu, 2007).

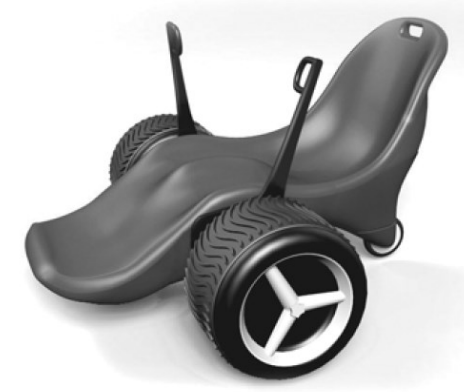

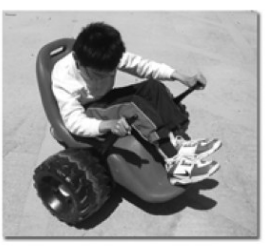

Child with Disability

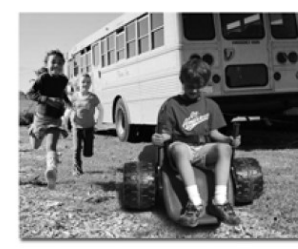

Child without Disability

Illustration 4. Play Racer

Here below, there's another example of a play children product developed by "Let's Play" at the University of Buffalo (New York), using the "From-disable-to-able" methodology. It is an accessible swing for children of different ages. It applies to all Design for all principles and benefit both children with functional diversity or any children who feels unsafe, scared, has back problems or does not like to be push by pushing his/her back.

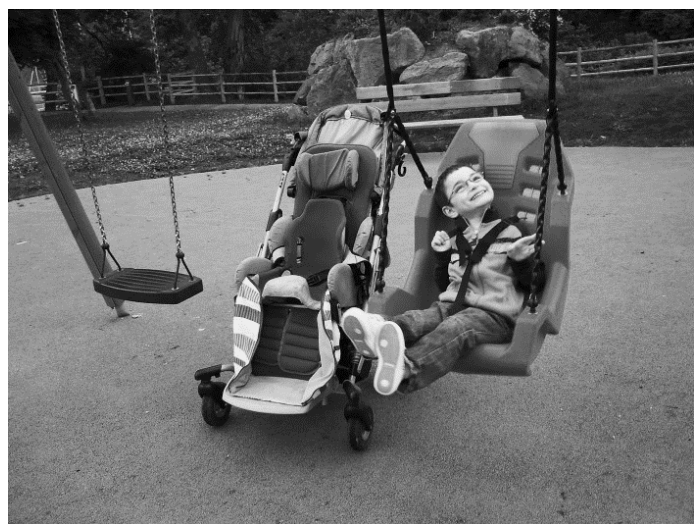

Illustration 5. Accessible swing 
Another interesting methodology is the one used by Emotional Research LAB. This software is able to use facial emotion recognition and eye tracking to understand how people feel in real life, in real time. It can be used to design new products focused on the user; in this case, the children. For example, it can capture and analyse their feelings when they see some toys in order to design a new toy according to their liking.

It follows the steps below:

$>$ Users' interview to know his/her facial expressions.

$>$ The users watch some videos about the products and their facial emotions are registered.

$>$ A graphic is generated with some feelings analyzed like happiness, surprise, fear or sadness.

$>$ Design decisions are taken depending on the results.
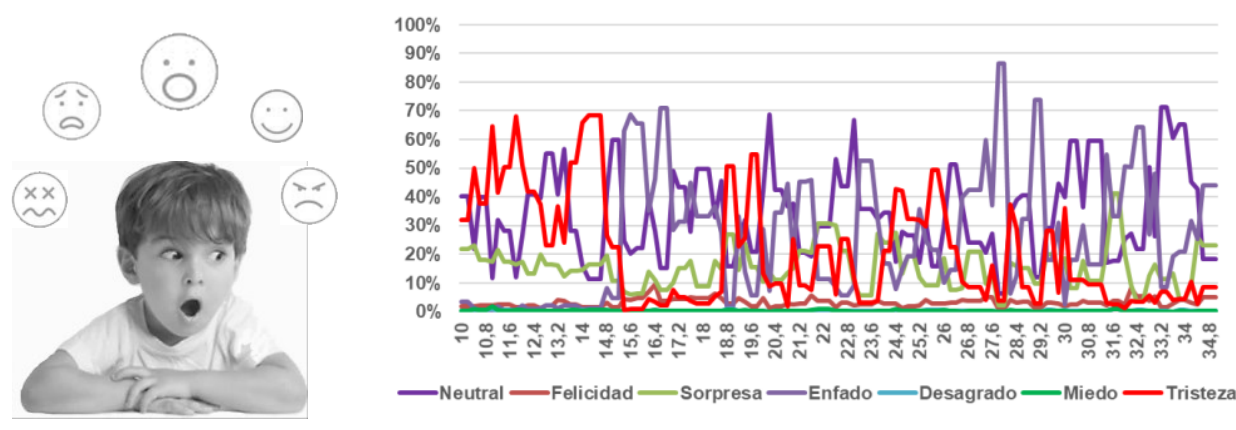

Illustration 6. Emotion Research LAB

\section{Conclusion}

Last year, I realize Universal Design is essencial for a good design (Centre for Excellence in Universal Design, 2014). And so far, I think it cannot be more true. It reflects the users' needs in all their diversity in benefit of both people with and without disabilities, and provides equally opportunities to fulfil everyone's potential. Its principles are the guideline every environment, product and service should follow. Specially, the Universal Design challenge is to develop accessible design for people who are in risk of social exclusion in order to improve their inclusion in our society (The Commission for Architecture and the Built Environment, 2006). However, the first step is education, empathy and awareness (Norman, 2009). Thus, inclusion practices and attitudes should be included in the education system and in any environment, services and product from the very early stages. As soon as 
inclusion is enhanced, exclusion practices will be reduced and children with and without disabilities will engage more actively as they grew, fulfilling their own potential (M. Beneito, 2017).

There are several inclusive didactics. However, it is time to mix them with Accessible Design and let it take its role, too(Bhatia, 2015). Although even Tsai Lu Liu (2007) defines play as the childhood occupation, and they have a crucial impact on children with disabilities inclusion the classrooms are laking in accessible products. "From-disable-toable" approach is a good toy product design methodology to follow as "Let's play" program displays (Letsplay.buffalo.edu, 2011). Educators should demand these products and constantly use them at their lessons. We are hopefully facing a world where designers together with educators seek Universal Design solutions as they definitely guarantee more adjustable, appealing and safer designs for all users.

\section{References}

M. Beneito (2017) "Universal design for children”.

Flood, E. (2010) Assisting children with special needs: An Irish perspective. Dublin: Gill \& Macmillan.

Burgstahler, S. (2015) Universal design of instruction (UDI): Definition, principles, guidelines, and examples. Available at: http://www.washington.edu/doit/universal-design-instruction-udidefinition-principles-guidelines-and-examples (Accessed: 6 May 2018).

National Disability Authority, Centre for Excellence in Universal Design. for E. in U.D. (2014) What is Universal Design. Available at: http://universaldesign.ie/ (Accessed: 7 May 2018).

Murray, C. and Urban, M. (2012) Diversity \& equality in early childhood: An Irish Perspective. Dublin: Gill \& Macmillan.

Nutbrown, C., Clough, P. and Atherton, F. (2013) Inclusion in the early years. 2nd edn. London: SAGE Publications.

The National Institute on Disability and Rehabilitation Research, U.S. Department of Education (1997). The centre for universal design - universal design principles. Available at: https://www.ncsu.edu/ncsu/design/cud/about_ud/udprinciplestext.htm (Accessed: 11 February 2017).

Department for children, schools and families, (2015) Designing for Disabled Children and Children with Special Educational Needs. 2015. Web. 29 Jan. 2017.

The Commission for Architecture and the Built Environment (2006) The principles of inclusive design: They include you. Available at: http://webarchive.nationalarchives.gov.uk (Accessed: 12 May 2018). 
Dr. Sunil Kumar Bhatia, Universal Design, Design For All. Modern Edge. N.p., 2015. Web. 2 Feb. 2017. Available at: http://modernedge.com

DO-IT, What is the difference between accessible, usable, and universal design? (2017). [online] Washington.edu. Available at: http://www.washington.edu [Accessed 19 May. 2018].

Lidwell, W., Holden, K. and Butler, J. (2003) Universal principles of design, Gloucester, MA: Rockport Publishers.

Schrott, H. (2009). Design for the Disabled. [online] WIPO MAGAZINE. Available at: http://www.wipo.int/wipo_magazine/en/2009/05/article_0009.html

Letsplay.buffalo.edu. (2011). (C) 2017 Dr Pepper Snapple Group, [online] Available at: http://letsplay.buffalo.edu/ [Accessed 4 Mar. 2018].

Norman, Donald A. The Design Of Future Things. 1st ed. New York: Basic Books/Perseus Book Group, 2009. Print.

Tsai Lu Liu, (2007). A From-Disabled-To-Able Approach To The Universal Design Of Children's Play Products. 1st ed. Auburn University, 2007. Print. 